\title{
Efeito placebo, efeito nocebo e psicoterapia: correlações entre os seus fundamentos
}

\author{
Danilo Assis Pereira* \\ Carolina Farnese**
}

\begin{abstract}
RESUMO - O presente artigo é um estudo exploratório da literatura acerca do que vem a ser placebo e nocebo, seus efeitos no organismo bem como suas possíveis interações com a psicologia. Os objetivos foram explicar como o placebo e o nocebo influenciam no pensar e no agir das pessoas e de que forma estão ligados à sugestionabilidade e à auto-cura de uma estrutura corporal e, ainda, expor as hipóteses explicativas de tais efeitos. Foram apresentados alguns tipos de placebos utilizados com eficácia e foi desenvolvida uma comparação entre o efeito placebo e a psicoterapia, levando em consideração, inclusive, o conceito e as explicações da psicossomática. Foi concluído que a relação direta entre conteúdos internos e o corpo físico permite tanto a somatização daqueles em doenças, como torna possível a cura das mesmas por vias semelhantes. Foi sugerida que uma possível mudança ideológica e de auto-confiança produzida pela consciência do efeito placebo e seus processos melhoraria a qualidade de vida, principalmente em termos de saúde.
\end{abstract}

Palavras-chaves: placebo, nocebo, psicoterapia, psicossomática, auto-cura, sugestionabilidade.

\section{Placebo and nocebo effects, and psychotherapy: correlations between its fundamentals}

\begin{abstract}
This paper is an exploratory study of placebo and nocebo effects, their effects in the organism and its possible interactions with psychology concerns. The aim of this paper was to explain how placebo and nocebo effects influence in people behaviors and thoughts, and explain their link between suggestibility and
\end{abstract}

\footnotetext{
*Professor de Psicologia do UniCEUB. Mestre em Psicologia (UnB). Orientador de monografia na área de Psicofisiologia. Psicólogo clínico do Instituto Brasiliense de Análise do Comportamento. E-mail: danilo.assis@uniceub.br

**Aluna do $10^{\circ}$. semestre de psicologia do UniCEUB. E-mail: carol.farnese@ brturbo.com O presente artigo foi baseado na monografia de final de curso do primeiro semestre de 2004 da segunda autora, sob orientação do primeiro autor.
} 
the body self-cure system. Yet, we point some hypothesis that could explain these effects. Some placebos used efficaciously were presented, and a comparison between placebo effect and psychotherapy was developed, considering psychosomatic concepts and explanations. We concluded that the direct relationship between inner contents and physical body can allow the somatization in diseases. And it makes possible the cure by similar ways. We suggested that a possible ideological change in self-trusting produced by the awareness of placebo effect, and its process, could increase life expectancy.

Key words: placebo, nocebo, psychotherapy, psychosomatic, self-cure, sggestibility.

Medicamentos têm sido utilizados pela humanidade há muito tempo, por diversos motivos e para vários propósitos. Destaca-se a finalidade terapêutica como a mais freqüente dentre a procura por fármacos. Em relação à terapia por remédios, existe um efeito que não está vinculado à farmacologia dos medicamentos, entretanto vem se mostrando eficaz em alguns tratamentos, tal efeito é conhecido como efeito placebo. Placebo é qualquer tratamento que se prescreve dizendo ser um procedimento ou medicamento ativo, contudo, na realidade, não tem ação específica nos sintomas ou doenças do paciente mas de alguma forma, pode causar um efeito no mesmo, assim, o resultado é apenas de natureza psicológica. Tal resposta não está limitada ao alívio de sintomas, como a dor, e tem sido constatado que o placebo, sob certas circunstâncias, trata-se efetivamente de um fator de cura mentecorpo, pois é capaz de facilitar o acesso às crenças e às expectativas em nível psicológico (Rossi, 1997).

Neste artigo pretendeu-se explicitar que a sugestionabilidade das pessoas, as crenças e as expectativas alteram o comportamento humano. Ou seja, a psiquê causa alterações no organismo fisiológico. Pretendeu-se, ainda fazer um levantamento das hipóteses mais recentes que examinam as bases do efeito placebo. Além disso, mostrou alguns tipos de placebos utilizados com eficácia e relacionou que alguns deles, mesmo que não declaradamente, atuam como tal, citando como exemplo a psicoterapia.

A palavra placebo deriva do latim, do verbo placere, que significa "agradar" e tem, isoladamente como definição, um tratamento inócuo, ou seja, é uma substância ou procedimento que não tem um poder inerente para produzir um efeito que é desejado ou esperado. $\mathrm{O}$ efeito placebo é quando se obtém um resultado positivo a partir da administração de um placebo (Benetton, 2002). Tal efeito é genuinamente psicológico ou fisiológico e é atribuído ao fato do recebimento de uma substância 
ou procedimento, mas que ocorre devido aos poderes inerentes destes (Williams, 2004). O placebo não se limita a medicamentos e pode aparecer em qualquer procedimento médico, tais como cirurgias e anestesias dentre outros (Benetton, 2002). Etimologicamente, o conceito de placebo traz em si a idéia de que se trata de uma medida adotada mais para agradar do que para efetivamente tratar os pacientes (Tostes, 1985).

O uso médico de placebos é muito antigo na história da humanidade. Pode ser encontrado em todas as sociedades primitivas e, no sentido amplo, o termo, está presente nos amuletos, simpatias e superstições que povoam a história das sociedades humanas. Com o passar do tempo, e à medida que os medicamentos foram se demonstrando eficazes, cresceu o interesse pelo estudo do efeito placebo. Não se tratava neste momento de negar ou de contestar a existência de um efeito farmacológico próprio dos medicamentos, mas de reconhecer que prescrever um determinado fármaco iniciava uma cadeia de eventos, e que, paralelamente aos efeitos farmacológicos existiam também efeitos psicológicos, que tinham importância própria e mereciam serem estudados, em virtude do importante papel que representavam na eficácia das terapias de sintomas danosos (Tostes, 1985).

O conhecimento sobre o efeito placebo ampliou-se muito com a necessidade que a medicina manifestou em realizar testes clinicamente controlados, que é uma metodologia científica muito utilizada para determinar a eficácia terapêutica de novos fármacos. Existem quatro tipos diferentes de estudos com medicações: abertos (sem grupo controle), de comparação (no qual uma das medicações é de eficácia comprovada), de comparação medicação versus placebo (às vezes incluindo três braços: medicação de teste, medicação convencional e placebo) e estudos de retirada de medicações (Elkis \& Gattaz, 2000).

Geralmente estudos com novas medicações são realizados em dois tempos: em um primeiro momento, a nova medicação é comparada com placebo e, no segundo, a mesma é comparada com outra de ação similar (Elkis \& Gattaz, 2000). Em linhas gerais, são estabelecidos, aleatoriamente, dois grupos de pacientes portadores de uma mesma condição (sintoma ou doença), na qual se deseja intervir. A um grupo é efetuada a intervenção, ao outro grupo, a intervenção é apenas simulada, com placebo (Castiel, 1991). Assim, por administrar placebo a um grupo controle, posteriormente torna-se possível comparar os resultados com os obtidos no grupo que recebeu a medicação ativa. Tal procedimento pretende demonstrar que quanto maior a diferença nos resultados entre o segundo e o primeiro grupo, maior a eficácia farmacológica da substância em estudo (Elkis \& Gattaz, 2000). Demonstrando uma superioridade do novo medicamento em relação ao placebo, seguidamente esta medicação é comparada a um outro fármaco, anteriormente comprovado como eficiente no mesmo objetivo. Tal procedimento confirmará, ou não, a eficácia da 
nova medicação para o resultado a que se pretende.

Outra utilização do placebo é quando o mesmo é ministrado intencionalmente a fim de que ajude na autoconfiança do paciente, com o objetivo de curar ou melhorar seus sintomas a partir da indução psicológica sem as possíveis conseqüências de uma intervenção medicamentosa ativa. Tal emprego do placebo aparece em procedimentos que se pretenda testar o poder da psiquê ou processos mentais através da confiança em algo ou alguém (Fish, 1988/1973).

O placebo, popularmente pode ser considerado como uma "mentira que cura", mas um melhor entendimento mostra que a cura não vem da mentira em si mesma e sim da capacidade do paciente em se curar por vias simbólicas e psicológicas, da mesma forma que por intervenção biológica (Benetton, 2002). Segundo Holden (2002), o placebo ativa no cérebro os mesmos circuitos que os analgésicos. Os dois produzem um aumento do fluxo sanguíneo em áreas ricas em receptores de opióides (faixa superior anterior do córtex) que mantém contato com outras regiões do cérebro, incluindo o córtex órbitofrontal, área que processa emoções. Assim, pessoas que apresentam respostas mais intensas ao placebo, possivelmente possuem este sistema de receptores mais eficiente, com uma maior concentração de elementos.

Estudos e pesquisas sobre o efeito placebo são cada vez mais freqüentes, principalmente devido ao fato de que as taxas de eficácia são muito altas, especialmente em psiquiatria (Amaral \& Sabbatini, 1999). Além disso, tais estudos

Tabela 1. Porcentagem de melhora com placebo nos diversos quadros clínicos

\begin{tabular}{ccc}
\hline Quadro clínico & \% média & Variação \\
\hline Dores em geral & 28,2 & $6-67$ \\
Dor de cabeça & 61,9 & $46-95$ \\
Enxaqueca & 32,3 & $20-58$ \\
Distúrbios gastrintestinais & 58,0 & $21-56$ \\
Ipertensão arterial & 17,0 & $0-60$ \\
Dores reumáticas & 49,0 & $14-84$ \\
Cólicas menstruais & 24,0 & $11-60$ \\
Gripe & 45,0 & $35-61$ \\
Alcoolismo & 22,0 & $10-50$ \\
\hline
\end{tabular}

(Adaptado de Meyer-Kindi - 1989/ in Rev. Bras. Med. Vol 54 nº 4 - 1997) 
levam em consideração que o placebo pode ter efeito positivo e negativo. Considerase bem sucedido quando o paciente relata alguma melhora, como se pode observar resumidamente na Tabela 1, e ao contrário, mal sucedido quando o relato é de surgimento de algum efeito colateral desagradável (Tabela 2). Neste segundo caso, o efeito é chamado de nocebo, palavra que tem origem do latim, do verbo nocere, e significa provocar dano, prejudicar.

Para se ter uma idéia do fenômeno placebo, a Tabela 1 seguinte, demonstra a proporção de pacientes que respondem positivamente aos placebos dependendo do tipo de distúrbio e sintoma a ser tratado.

A Tabela 2 demonstra os efeitos colaterais (nocebo) que se pode observar, em alguns casos, a partir da utilização de placebo.

Tabela 2. Sintomas indesejados e efeitos colaterais induzidos pelo uso do placebo

\begin{tabular}{cc} 
Sintomas & Frequência $(\%)$ \\
\hline Curticária & 5 \\
Pesadelo & 8 \\
Sonolência & 23 \\
Cansaço & 41
\end{tabular}

Dificuldade de concentração

Cefaléia

Irritabilidade

Insônia

Boca seca

Náusea

Obstipação intestinal

Obstrução nasal
27

15

17

7

5

5

4

31

(Adaptado de Meyer-Kindi - 1989/ in Rev. Bras. Med. Vol 54 nº 4 - 1997) 
Em relação aos efeitos expostos nas tabelas, é importante ressaltar a influência da expectativa do paciente que apresente efeitos colaterais (nocebos) a partir de um placebo, visto que esta expectativa, em relação ao tratamento, é um dos fatores que determina seu efeito. Ou seja, se houver uma expectativa negativa, pessimista, o paciente tenderá a apresentar uma reação nocebo, ainda que saibamos que a substância é quimicamente inativa. Desta mesma forma, a expectativa quando positiva e otimista, gera a reação placebo (Baleeiro \& Baleeiro, 2000).

Baleeiro e Baleeiro (2000), relatam uma pesquisa feita com voluntários sadios, comparando o uso de um colírio placebo com o uso de um colírio que apresentava propriedade farmacológica. Nesse trabalho foram registradas respostas indesejáveis, reação nocebo, em $27 \%$ dos voluntários sadios que fizeram uso de colírio placebo.

Spiegel (1997, citado em Baleeiro \& Baleeiro 2000) descreve um relato em que um fator sociocultural interferiu na vida de um paciente, acarretando o fenômeno nocebo. Um paciente na enfermaria de cardiologia apresentava-se clinicamente desenganado e solicitou um padre para administrar-lhe a extrema-unção. Quando Dr. Spiegel retornou à enfermaria, encontrou o padre exercendo sua função erroneamente ao paciente do leito ao lado daquele que havia solicitado sua presença. Quinze minutos depois, o paciente que recebera o ato litúrgico faleceu.

Como coloca Baleeiro e Baleeiro (2000), a atuação do placebo depende de alguns fatores básicos. Em primeiro lugar, a expectativa e comportamentos do paciente, bem como de seus familiares é quase sempre inconsciente. A atitude médica também é relevante, seu propósito, sua compenetração, seu poder de persuasão, sua expectativa de cura, seu nível de satisfação, seu equilíbrio emocional e o ritual de prescrição. A importância da figura do médico no processo de cura pode ser constatada quando, por exemplo, um paciente não melhora com um profissional e melhora com outro, apesar de ter sido usada a mesma medicação e na mesma dosagem (às vezes, com nome comercial diferente) (Ballone \& Ortonlani, 2003). O placebo em si, também interfere na atuação, o tipo de administração adotada (invasiva ou não), os custos, a aparência do medicamento (cor, tamanho) e a quantidade administrada. Existe uma preferência estatisticamente comprovada para a eficácia dos placebos de uso tópico em comparação com aqueles usados por via oral (Ballone \& Ortonlani, 2003).

Outro fator que influencia no fenômeno placebo é a interação paciente-médico, o efeito como conseqüência de uma relação sadia e eficaz, fundamentado na confiança do paciente e na postura do profissional. Um paciente pode se sentir melhor apenas pelo fato de estar sendo atendido, de estar sendo ouvido e compreendido, e devido à relação de entrega (Benetton, 2002). A parte psicológica da doença é amplamente aceita pela cultura médica moderna. Mudou-se o conceito primário que levava em consideração apenas os aspectos biológicos, adotando uma mentalidade dualista, 
o que gerou a psicossomática. Assim, admite-se atualmente, a existência do fator psicológico na causa do adoecer (Baleeiro \& Baleeiro, 2000).

Além dos fatores citados, uma grande exigência para a eficácia do placebo é a de que o paciente deva estar ciente de que algo está sendo feito por ele (Stephen, 2002). O paciente projeta seu poder no profissional, mas reintrojeta via placebo. Assim seu "curador" interior, que ainda necessita de estímulos para se mobilizar para a cura dos sintomas, desperta incentivada pelo placebo (Benetton, 2002).

Em 1998, Brown (citado em Horgan, 2002), mencionou um estudo no qual pacientes asmáticos inalavam uma névoa composta apenas de alergênicos (substância capaz de produzir alergia) que poderia agravar sua asma, seus pulmões

se contraíam mais e aumentava sua dificuldade para respirar. Quando lhes apresentavam a mesma névoa e diziam que continha medicamento antiasmático, os pacientes respiravam com maior facilidade.

Segundo Gerhardt (2001) existem três condições médicas nas quais o efeito placebo já foi, repetidas vezes, constatado como sendo eficaz, dor, depressão e Mal de Parkinson. As três desordens estão associadas á disfunção de neurotransmissores no sistema nervoso central, e foi detectado que a liberação destes, é um mecanismo comum do efeito placebo em tais condições.

Celestino (1992) desenvolveu uma pesquisa com 157 mulheres com idades variando entre 40 e 69 anos. O objetivo era o de estudar o efeito placebo sobre os sintomas comuns em pacientes climátericas. Foram dadas orientações higienodietética, bem como a prescrição do placebo que era ministrado uma vez por dia. Os resultados demonstraram que houve melhora sintomática em 89 pacientes, o que equivaleu há $56,6 \%$ da amostra. Efeitos colaterais foram evidenciados por 32 pacientes, 20,3\% da amostra. Celestino concluiu que o placebo é uma alternativa terapêutica válida, sobretudo em casos de contra-indicação ou dificuldade de controle adequado da hormônioterapia substitutiva.

Surgem então algumas questões: o que realmente causa o efeito placebo? Nos tratamentos com placebo que apresentem eficácia de resultados, o que leva a cura dos sintomas? De que forma o organismo se mobiliza para melhorar os sintomas a partir de sua exposição ao placebo? Como meios para obter tais respostas, levantamse algumas hipóteses.

\section{Hipóteses da eficácia do placebo}

Ainda hoje não se chegou a um consenso do que especificamente causa o efeito placebo, porém, existem algumas hipóteses explicativas (Amaral \& Sabbatini, 1999). 
Uma das categorias refere-se às teorias de condicionamento, ou reflexo condicionado, desenvolvidas por Ivan Pavlov, em 1902, que antes de alimentar um grupo de cães de laboratório, soava uma campainha, e assim conseguia induzir nos cães intensa salivação apenas com o soar da campainha, mesmo fora do horário das refeições. Supõe-se, então, que o indivíduo faça uma associação entre o estímulo (placebo) e uma experiência anterior de ter obtido uma melhora e sensação de bem estar após ter tomado um medicamento, ou após ter tido contato com médicos e informações pertinentes ao sintoma (Epstein, 2002). Ou seja, o condicionamento operante pode ocorrer quando o comportamento é gratificante, assim, pessoas com história de respostas favoráveis ao tratamento são mais aptas a reagir bem (Jarvis, 2001, citado em Epstein, 2002).

Uma outra teoria explica o fenômeno como decorrente da sugestionabilidade da pessoa. Pessoas são predispostas a acreditar em coisas de diversas maneiras e em graus variados (Stephen, 2002). Sugestão é o ato pelo qual uma idéia é aceita pelo cérebro, seja ela verdadeira ou falsa. O sistema nervoso central avalia e classifica informações recebidas do meio externo, se perceber como algo ameaçante, desencadeia no organismo uma reação de rejeição ou de oposição, de luta ou fuga ante tal ameaça. Em contrapartida, se algo for recebido como tranqüilizador ou reparador, certamente promoverá efeitos opostos. Assim, o organismo emite certo comportamento correspondente à avaliação efetuada sempre de forma global, integrada e envolvendo reações psíquicas e orgânicas (Campos, 1985).

Existe a explicação de que o placebo diminui a ansiedade do paciente e assim alivia sintomas causados pela reação do corpo à tensão (sintomas psicossomáticos) (Stephen, 2002). Uma explicação fisiológica descreve que o placebo atua a nível de atividade neurológica e química cerebral (Petrovic, 2002, em Epstein, 2002). Epstein (2002), defende que o placebo e o nocebo levam à saúde ou à doença via modulação mental dos sistemas autônomo, endócrino e imunológico.

Alguns pesquisadores acreditam que pelo menos parte do efeito placebo se deve a uma doença ou lesão seguindo seu curso natural. Nós, muitas vezes, nos curamos com o tempo, mesmo se não fizermos nada para tratar uma doença ou lesão. O placebo é, segundo esses pesquisadores, às vezes erroneamente considerado como eficaz quando, na verdade, é o corpo que está se curando espontaneamente (Stephen, 2002).

O corpo humano se curando espontaneamente pode ser explicado devido ao fato de existir no organismo um sistema imunológico que representa o terceiro maior sistema regulador do corpo humano, e tem como função resistir a quase todos os tipos de organismos invasores ou toxinas que poderiam danificar a estrutura corporal (Rossi, 1997). No sangue existem inúmeras células e moléculas (lisossomos, polipeptídios e proteínas) responsáveis pela destruição de bactérias, vírus, toxinas 
e outros elementos patogênicos, que venham a invadir o organismo. Estas células são restituídas na proporção de um milhão por segundo em seres humanos e estão preparadas para atuar assim que o organismo perceba a invasão patológica até que os elementos sejam totalmente eliminados (Perlson, 1988, citado em Rossi, 1997). Segundo Sternberg (2004), o cérebro e o sistema imunológico enviam sinais um ao outro continuamente, em geral pelas mesmas vias, o que pode explicar como o estado mental influencia na saúde. Esses sinais também afetam o comportamento, induzindo-os para que ajudem na recuperação de doenças ou ferimentos. O sistema imunológico opera como uma rede descentralizada, respondendo automaticamente a qualquer agente que invada ou perturbe o funcionamento do corpo. As células imunes geradas na medula óssea, linfonodos, baço e timo, comunicam entre si através de pequenas proteínas. Esses mensageiros químicos mandam sinais ao cérebro, pela corrente sanguínea ou por via nervosa. O limiar de tais reações ou seja as diferenças de respostas individuais são, até certo ponto, determinadas geneticamente, além de fatores ligados ao desenvolvimento na infância, aprendizado e experiências posteriores.

Segundo Celestino (1992) é possível que o placebo ou qualquer medicamento por serem corpos estranhos a um organismo, quando ingeridos, acionem neste uma resposta imune no decorrer de um tratamento. Contudo, corpos estranhos podem ser bons antígenos. Como antígenos, medicamentos podem eliciar uma resposta imune, não somente pelo seu efeito nocivo potencial, mas também pelo fato de perturbar o meio interior. O sistema imune tem a capacidade de discriminar corpos estranhos por estes se diferenciarem da imagem interna dos constituintes do organismo, valendo-se da grande variedade de reações específicas de suas células. A resposta imune, como resposta homeostática (tendendo a estabilidade interna), contribui, portanto para a manutenção da constância e integridade dos tecidos e células do corpo.

Apesar de o placebo ser considerado como uma "mentira que cura", alguns autores defendem que os médicos não precisam enganar os pacientes sobre a natureza do mesmo para que se observe algum efeito benéfico nos tratamentos que o utilizam (Horgan, 2002). Há indícios de que os pacientes respondem positivamente ao placebo mesmo quando sabem exatamente do que se trata. Em um estudo, em 1965, com quatorze pacientes deprimidos, todos receberam placebo por uma semana. Embora os pacientes fossem informados de que os comprimidos não possuíam efeito farmacológico, seis deles acreditavam e diziam que, na verdade, os comprimidos continham medicamento. Todos os quatorze pacientes, mesmo aqueles que aceitaram a informação que se tratava de uma substância inerte, responderam positivamente durante a semana de tratamento. Rossi (1997) afirma que mesmo tendo consciência de estar utilizando um placebo, se o paciente apresentar determinadas características 
e atitudes, o efeito é concreto. Cita como características necessárias a ausência de pânico diante dos sintomas, confiança em sua habilidade física para utilizar sua própria capacidade para a cura, bom humor e contentamento que geram um ambiente promissor e curador para si mesmo, se responsabilizar pela sua cura, ou por parte dela numa relação de parceria com seus médicos, além de criatividade e otimismo.

Cousins (1979, citado em Rossi, 1997), afirma que atitudes e emoções positivas são a essência do bem-estar e da resposta placebo. Declarou que o placebo é o "médico que mora em nosso íntimo".

O uso do placebo por profissionais de saúde é uma questão ética e não apenas um problema de metodologia cientifica. Quando utilizado na clínica, apresenta a falta de um atributo na relação médico-paciente, a confiança na relação profissional. Quando utilizado em pesquisas, cobaias humanas são submetidas a riscos desnecessários (imprudência e negligência por parte do profissional ou piora dos sintomas). (Uso do Placebo: Aspectos Bioéticos, 2002).

Para avaliar questões éticas em pesquisas, foram criadas instituições do tipo CONEP (Conselho Nacional de Ética em Pesquisa em Seres Humanos), que se fundamenta na resolução CNS n 196/96 (Uso do Placebo: Aspectos Bioéticos, 2002). Existe ainda as CEPs (Comissão de Ética em Pesquisa), de caráter local ou institucional. A CONEP coordena as redes de CEPs, todos os projetos de pesquisa devem ser previamente aprovados pela CEP da instituição em que serão realizados, esta deverá ser credenciada à CONESP, que em última instância aprovará ou não a realização da pesquisa (Cortese, 1999).

A legislação sobre pesquisas clínicas, seu conjunto de normas, regulamentações nacionais, resoluções e portarias específicas visam o bem estar e segurança dos pacientes que aceitam participar destes projetos. Para tal, os órgãos responsáveis analisam os riscos e benefícios das pesquisas, fazendo um levantamento dos dados da equipe que, necessariamente, deve conhecer não só os pormenores legais como avaliar os efeitos benéficos, além das possíveis reações adversas, observando a influência dos resultados finais e a utilidade da pesquisa realizada. As realizações de pesquisas clínicas seguem etapas preestabelecidas e reguladas por normas e padrões internacionalmente aceitos (Cortese, 1999).

\section{Psicoterapia: conceitos gerais}

Além dos medicamentos e seus efeitos no organismo, existem outras formas de se obter a cura ou diminuir efeitos desagradáveis presentes no organismo humano, podendo tais métodos atuar tanto fisicamente quanto psicologicamente. Em relação 
à atuação psicológica, podemos citar como metodologia comprovadamente eficaz as psicoterapias. Faz-se necessário, desta forma, uma descrição particularizada da mesma.

As abordagens psicoterápicas são talvez as mais antigas modalidades terapêuticas conhecidas na história da medicina. Desde os primórdios, sabemos que os seres humanos influenciam-se uns aos outros de diversas maneiras, tanto no sentido positivo quanto no negativo (Tostes, 1985).

Os anos 50 do século passado marcaram o início do interesse e do movimento para analisar e comparar a eficácia das psicoterapias, aplicando-se metodologia cientifica apropriada (Bechelli \& Santos, 2002). Nos anos 80, pesquisadores chegaram ao consenso sobre a superioridade da psicoterapia em relação à ausência de tratamento. Ao mesmo tempo em que mostraram que não existe superioridade de um sistema psicoterápico (modelo teórico e técnicas pertinentes) em relação a outro em termos de resultados (Bechelli \& Santos, 2002).

Entende-se por psicoterapia uma forma de tratamento em que uma pessoa treinada, utilizando meios psicológicos, auxilia outra a rever seus problemas, visando restabelecer o equilíbrio emocional de um indivíduo (Cordioli, 1993). Além disso, a psicoterapia pode beneficiar todo aquele que deseja aprofundar o conhecimento de si mesmo, a partir do contato interpessoal. É um processo que tem por objetivo modificar padrões de comportamento inapropriados que dificultam o processo de desenvolvimento pessoal (Wolberg, 1998 citado em Bechelli \& Santos, 2002).

Um psicoterapeuta é um profissional especializado em saúde mental que desenvolve suas técnicas baseadas nas seguintes características do paciente: gravidade do transtorno mental, motivação para mudança, capacidade de se relacionar e confiar, força do ego (tolerância, flexibilidade, criatividade), mentalidade psicológica (verbalizar pensamentos, compreender seus problemas) (Bauer, 1987 citado em Bechelli \& Santos, 2002). O terapeuta exerce influência sobre a mudança do paciente, valendo-se de recursos como intervenções verbais, comunicação não-verbal e ambiente psicoterápico estruturado (Cordioli, 1993). A aliança terapêutica (pacienteterapeuta) é considerada um fator comum nas psicoterapias, à medida que não se prende a um tipo especial de psicoterapia ou a uma determinada escola teórica, e há evidência substanciosa de impacto positivo da mesma no resultado dos tratamentos (Iacoponi \& Marcolino, 2001).

A motivação do paciente para a mudança é um componente fundamental para a eficácia do tratamento psicoterápico, assim o paciente aceita e colabora com o trabalho de procurar do seu próprio bem estar. O terapeuta oferece ao paciente condições para desenvolver sua própria mudança através das técnicas e elementos verbais que ativam o potencial e a propensão natural de recuperação, o paciente 
traduz o aprendizado obtido na terapia em informações que faça sentido para sua vida (Bechelli \& Santos, 2002).

A literatura indica uma variedade grande de modelos de psicoterapia, Karasu (1977, citado em Cordioli, 1993) referiu existirem mais de 400 tipos diferentes de psicoterapia, que nada mais são do que mediadores de processos de mudança do paciente. Todos os sistemas possuem fundamentalmente o mesmo processo, baseado em idéias de que o simples ato de expressar suas preocupações, muitas vezes favorece ao paciente uma atitude de reavaliar e recompor seu problema e colocá-lo em nova perspectiva. Além disso, o feedback que o paciente recebe do terapeuta informa dados a seu respeito e lhe possibilita a chance e liberdade de fazer correções necessárias. Tais modelos variam de acordo com os psicólogos e com o paciente, de modo a ficar mais compatível com suas formas de agir na vida (Bechelli \& Santos, 2002).

Scazufca e Matsuda (2002) mostram uma pesquisa em que antidepressivos e psicoterapias foram utilizados no tratamento de pessoas idosas com depressão. Tal pesquisa mostra que muitas vezes pessoas idosas necessitam de outras medicações e os antidepressivos podem ser contra-indicados dependendo de sua interação com outras drogas, tornando sua aceitabilidade difícil. Assim os tratamentos psicológicos tornam-se uma opção atrativa para essa população, além da preferência das pessoas idosas por abordagens não medicamentosas para seus problemas de saúde.

A existência de elementos psíquicos e emocionais nos desvios dos estados normais dos organismos é algo de concordância entre a medicina e a psicologia. Tal afirmação pode ser confirmada pela existência da psicossomática como explicação de causas de doenças e sintomas, além da utilização do conceito de somatização pelas duas áreas.

\section{A relação mente-corpo}

Estudos têm mostrado que a medicina aceita o componente emocional no adoecer, já que reconhece a medicina psicossomática e as somatizações (concentração de energias psíquicas no corpo, causando algum sintoma físico). Difícil, entretanto, é convencer alguns médicos do mesmo componente emocional para a cura, da importância do conforto afetivo, do otimismo, da confiança, etc, no restabelecimento da saúde. o que facilitaria muito seus procedimentos e eficácia nos tratamentos (Ballone \& Ortolani, 2003).

A compreensão de que havia uma relação entre mente e a possibilidade de adoecer data de muito tempo atrás. Foi Hipócrates quem descreveu pela primeira 
vez o fenômeno que é chamado atualmente de psicossomática (Castiel, 1991).

Psicossomáticas são perturbações ou lesões orgânicas produzidas por influências psíquicas. Existe uma relação de proximidade entre a atividade emocional e a função neurovegetativas simpáticas, o que explica a ocorrência das modificações fisiológicas que não se manifestam, pois, estão ocultas nos estados de medo, fome, dor e raiva (Castiel, 1991).

Franz Alexander (1989, citado em Castiel, 1991) postulou que os denominados distúrbios neurovegetativos seriam respostas-padrão à situação de conflitos internos, sempre as mesmas para cada doença psicossomática. Haveria desta forma uma manifestação específica para cada tipo de conflito, assim descreveu as mesmas combinações de situações internas básicas em algumas patogêneses, ou seja, cada doença teria seu perfil psicológico correspondente, construído a partir das experiências infantis básicas.

As manifestações psicossomáticas podem ser agudas, recorrentes ou crônicas, brandas ou severas, desencadeadas de modo brusco ou insidioso. Podem ser bem definidas ou disporem de uma grande variação, onde é difícil distinguir saúde da doença (Campos, 1985).

A doença pode se originar diretamente de causas psíquicas, considerando uma construção psicofisiológica do indivíduo, onde cada componente possui funções particulares, conforme seja considerado no todo ou em parte. Assim cada constituinte pode ser tanto independente (agente), como recipiente das influências do resto do organismo. A doença tem uma razão de ser, ela expressa simbolicamente um conflito intimo e o impede de chegar à consciência, por efeito de recalcamento (D’épinay, 1988, citado em Castiel, 1991).

Castiel (1991) descreve a psicossomática como uma manifestação corporal que ocorre devido ao fato da ausência de representação, faz com que a libido e a agressividade de confundam e se transformem em energia pulsional indiferenciada, que ao atingirem o corpo, o lesam por não disporem de veículo de representação. Trata-se de uma forma de garantir o equilíbrio psíquico.

\section{Discussão}

Comumente, observamos profissionais da saúde fazendo afirmativas tais como: as doenças podem ser curadas apenas a partir da alimentação do paciente; por medicamentos naturais alternativos; pela íris dos olhos, argumentando ser esta um mapa do corpo; pela coluna vertebral, como sendo reflexo das doenças, que podem ser curadas apenas com exercícios de postura corporal; por aplicações

de estímulos em determinados pontos das orelhas com finalidade de atingir um 
equilíbrio da saúde; dentre vários outros exemplos. Alguns profissionais de saúde muitas vezes se vangloriam da eficácia de suas técnicas, esquecendo que um fator importante na cura do paciente é sua capacidade de auto-cura, algo essencial, ou seja, o poder intrínseco do paciente em restabelecer a própria saúde. Até mesmo os psicólogos não estão imunes de elevarem seu status pessoal pela presunção.

Existem vários métodos de promover e facilitar o poder de auto-cura de uma pessoa, todos os profissionais de saúde, mesmo sem intenção, se utilizam de algum meio que ative o "médico interno" que cada ser humano tem e é devido a tal fato que se tem a eficácia nos tratamentos. Segundo Celestino (1992), quando se emprega o placebo em um tratamento, exclui-se somente a atuação de uma substância quimicamente ativa do ritual de cura no processo terapêutico, mas não exclui outras variáveis ou forças sociais que continuam a atuar no paciente.

O seguinte trabalho não tem a intenção de diminuir ou contestar a eficácia (comprovada) da farmacologia e dos procedimentos médicos utilizados, mas sim demonstrar a capacidade inerente de cura do ser humano, e a eficácia da aliança que se estabelece entre os profissionais e seus procedimentos e essa capacidade dos pacientes.

O placebo é algo que se demonstra ser eficaz para ativar mecanismos de auto-cura de alguns pacientes, pois não age pontualmente no sintoma, apenas gera uma expectativa que ativam mecanismos internos que por sua vez agirá nos sintomas. As intervenções por placebo atuam mais como um coadjuvante de outras técnicas terapêuticas do que como método básico de tratamento e tem comprovadamente mostrado bons resultados.

Uma das formas de se utilizar placebo é ministrando-o como medicamento. Em relação a isto, Horgan (2002) fala sobre a existência de uma ameaça econômica dos psiquiatras para com os psicólogos, pois os psiquiatras podem receitar drogas que são mais baratas e mais rápidas do que a terapia pela fala, que é um procedimento que também se mostra eficaz na auto-sugestão de pacientes. A credibilidade que os médicos tem com a população em geral e a relativa imediaticidade do processo de melhora gera uma tendência maior de procura por eles.

Os psicólogos apesar de não poderem receitar psicofármacos no Brasil, também podem utilizar-se de métodos eficientes para cura ou melhora dos pacientes. A psicoterapia mostra a base para mudança ou sugere aceleração das taxas de mudança e ainda previne contra recaídas. Tem como base a idéia de que se o paciente acredita que será "curado" através da psicoterapia, então provavelmente será "curado".

O papel do terapeuta é fundamental na psicoterapia. Ele ocupa-se com aspectos da vida emocional e afetiva do paciente, trabalha no sentido do esclarecimento das dificuldades apresentadas pelo paciente, auxiliando-o a remover obstáculos que perturbam o curso do desenvolvimento. As técnicas e abordagens 
em psicoterapia são utilizadas como mediadores de processos de mudança (assim como o placebo atua). Além disso, a auto-revelação, o aprendizado por intermédio do outro e a aquisição de esperança em seu tratamento são mecanismos que potencializam o processo de elaboração das mudanças psíquicas, que levam o individuo a examinar os problemas e, se possível, solucioná-los de modo a lidar de forma mais crítica e adequada com a realidade.

O que se utiliza na psicoterapia para atingir um objetivo são as experiências do paciente, suas lembranças e as expressões de seus sentimentos, a empatia do terapeuta, sua atenção, sua capacidade evocativa e resolutiva, além dos sentimentos do paciente em relação ao terapeuta e principalmente a credibilidade no processo, de ambas as partes. Sobre este último, comenta-se que a parte da crença do psicólogo na eficácia do tratamento fica subentendida, no mínimo, pelo fato de que uma pessoa estuda psicologia por acreditar na eficiência da psicoterapia, senão, todos os anos de formação teriam sido em vão. Focando o paciente, o fato de estar se submetendo a uma psicoterapia indica que exista um mínimo de credibilidade e aceitação de que ela pode ajudar - o que é de interesse do paciente.

Enquanto metodologia, qualquer escola psicoterápica emprega procedimentos que põem a palavra em primeiro lugar (Cordioli, 1993). Como exemplo, podemos citar a psicanálise, na qual se espera que o inconsciente se manifeste pela associação livre de palavras, desde que faça emergir os afetos nela contidos, nas abordagens que empregam a dramatização, é necessário que o sujeito fale, assumindo seus papéis.

A principal preocupação de um psicólogo é o bem estar do seu paciente (Cordioli, 1993). Assim, muito do que é dito é mais focado no efeito que terá no paciente do que na verdade, e ainda assim o terapeuta estará agindo conforme a tradição psicoterápica. Podemos aqui traçar um paralelo com a utilização do placebo, que tem como foco a melhora do paciente, e neste caso utiliza-se de uma omissão da verdade para atingi-la.

Na psicoterapia, inicialmente, o terapeuta não pode afirmar ao certo qual técnica a ser utilizada será mais eficaz em cada caso, apesar de ter uma grande intuição. Assim, o psicólogo experimenta algumas técnicas sem ter certeza total do resultado, cria apenas uma expectativa positiva em relação ao objetivo a ser atingido. $\mathrm{O}$ fato de que se espera para comprovar se a técnica é eficaz em cada caso em específico, não é comunicado ao paciente. Fato semelhante acontece na utilização de placebo, o médico apesar de ter uma expectativa positiva em relação ao tratamento, não pode concluir que o placebo será eficaz e principalmente não deve transmitir tal insegurança para o paciente.

Uma das práticas bastante utilizadas em psicoterapia é a de persuadir o paciente de que sua queixa é comum também a outras pessoas, que ele não é o único a 
possuir tais sentimentos e que existem vários casos e pesquisas a respeito da causa de seu sofrimento (Fish, 1988/1973). Assim, o paciente se sente confortável e confiante na "cura", o que fatalmente será fator condutor para tal. Tal aplicação constitui em si mesma em uma comunicação por placebo, e pode promover a cura ou melhora, dentre outros fatores, devido à obtenção da informação por uma fonte conceituada, na qual se confia. Podendo esta ser o próprio psicólogo ou algum livro recomendado por ele. Tal fato mostra o nível de sugestionabilidade e a capacidade de auto-cura do paciente.

Foucault (1991/1972) evidencia em sua obra o deslocamento dos poderes que atuam sobre os loucos (pacientes) no decorrer dos tempos. Descreve a relação de poder que, em determinado momento, o médico adquire, na qual ele assume uma postura paternalista com relação ao paciente. Em nome da beneficência, a decisão tomada pelo médico não leva em consideração os desejos, crenças ou opiniões do paciente. O médico exerce, segundo Foucault, não só a sua autoridade, mas também o poder na relação com o paciente. O processo de tomada de decisão é de baixo envolvimento, baseando-se em uma relação de dominação por parte do médico e de submissão por parte do paciente. Tal fato é repercutido na sociedade até hoje, na submissão, na imagem e "confiança" que se tem na figura do médico, gerando uma soberania para esta classe.

Baseado na cultura, um fator relevante para o efeito positivo do placebo é a existência de uma consideração e condescendência por parte da população em geral, para com a figura do médico, do psicólogo e outros profissionais de saúde. Tal respeito gera certa obediência e aceitação, devido ao sentimento de submissão. Em outras palavras, o médico e o psicólogo têm um poder subjetivo, inerente, que faz com que sua simples presença já atue sobre o paciente, por ter acesso ao corpo do paciente ou a sua intimidade psíquica, pode penetrar e retirar sofrimentos, restaurar ou mutilar. Essa figura identifica-se simbolicamente com nossas figuras paternais, que sobre o corpo exerciam todo o poder, e que cuidavam quando apresentavam fragilidade e dependência, dando-nos acolhimento e proteção (Campos, 1985).

As condições prévias para a realização de qualquer terapia e especialmente nas terapias que se utiliza placebo e nas psicoterapias, compreendem não somente no terapeuta e seu paciente, mas também no contexto terapêutico em si (local e técnicas utilizadas), no modo de pensar do profissional e do paciente a respeito da mesma, ou seja, quais são os interesse por parte dos dois na terapia e quais foram suas experiências anteriores.

A seqüência do tratamento de uma psicoterapia e de uma terapia, que se utiliza de placebo, se assemelha em suas estruturas e pode ser comparada por suas semelhanças, como apontado na Figura 1. 


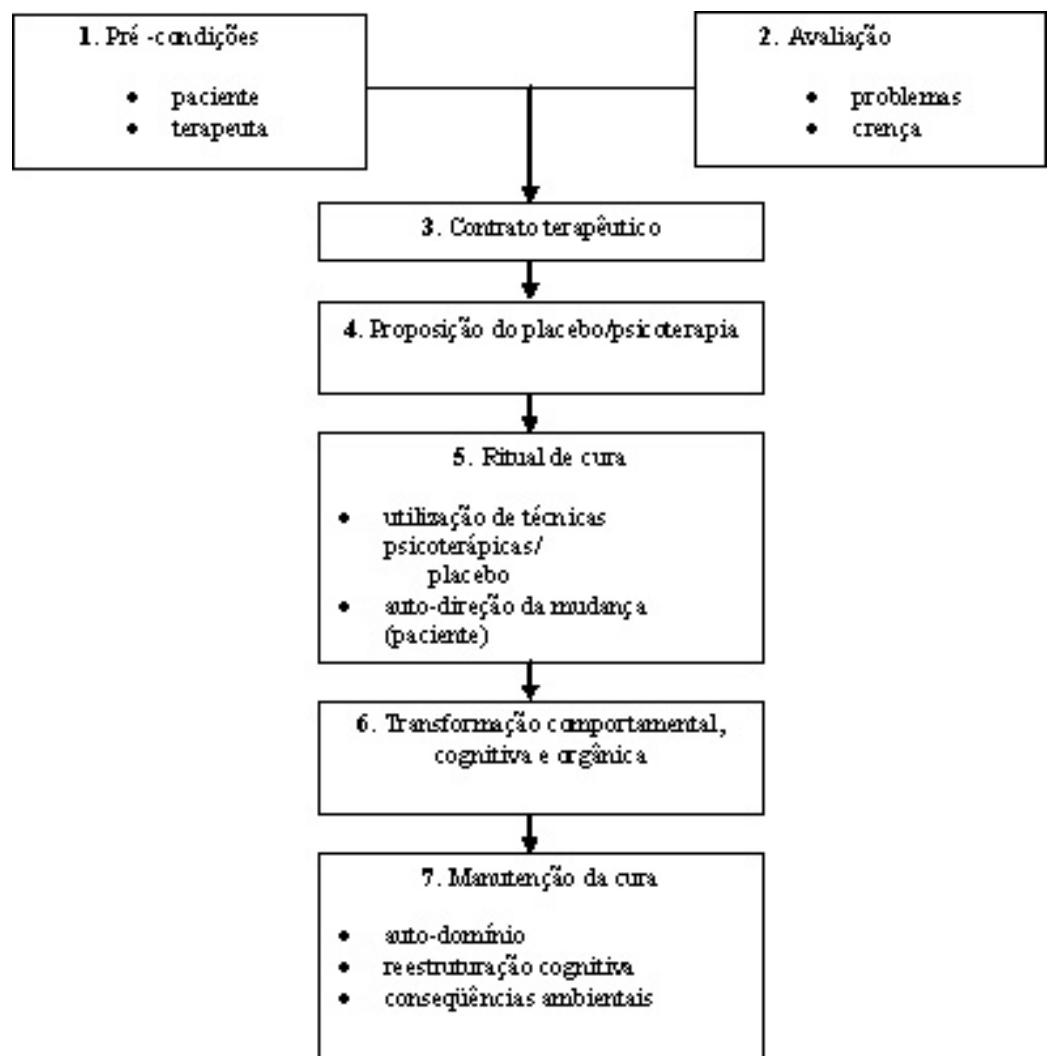

Figura 1 - Esquema de comparação de uma terapia que utiliza placebo e uma psicoterapia. Adaptado de Fish, 1988/1973.

Em relação à ilustração pode-se observar que inicialmente é necessário, tanto para uma terapia que se utiliza de placebo quanto para uma psicoterapia, a existência de um paciente e de um terapeuta para que haja uma exposição e avaliação da queixa e das crenças.

O contrato terapêutico é uma das pedras fundamentais para ambas as terapias (Fish 1988/1973). Para compreender e atingir a melhora do paciente, assim como para receitar um placebo, o terapeuta procura abordar as crenças mais firmes do seu paciente, ou seja, sua área de fé, aquilo que é parte integrante da vida da pessoa. Procura compreender as crenças para conseguir formular uma estratégia terapêutica 
ou um placebo eficiente.

O terapeuta busca formular um sistema eficaz de comunicação (inicialmente com a proposta terapêutica) para assim ativar um poderoso conjunto de crenças, que mudará outro conjunto de crenças, seus problemas. Comparando uma psicoterapia com placebo, trata-se de uma relação de significante a significado, onde a passagem para a expressão verbal provoca o desbloqueio do processo fisiológico (Castiel, 1991). Neste caso, o placebo assim como o psicólogo, toma uma postura ativa ao proporcionar representações para o paciente. Tanto na psicoterapia como no placebo, trata-se de induzir uma transformação (orgânica ou psicológica) que constitui essencialmente numa reorganização estrutural, a nível de psiquismo inconsciente, atuando no psiquismo ou a nível de corpo físico. A eficácia simbólica consistiria precisamente nesta propriedade indutora.

Assim, o terapeuta faz uso da convicção íntima do próprio paciente, através de técnicas psicoterápicas ou placebo, para incentivá-lo a ter uma experiência terapêutica de conversão, ou seja, mudar. Para tal, é importante convencer o paciente de que ele tem condição de superar os seus problemas, deixar claro que a responsabilidade é dele mesmo e não do terapeuta, e que são atitudes próprias que promoverão sua cura, mostrar que o paciente é o senhor do seu comportamento e não escravo dele. Posteriormente, havendo uma conscientização por parte do paciente de que é ele próprio que esta se curando, se sentirá influenciado por poderosas forças psicológicas internas que o impulsionarão na direção da mudança, ou seja, se sente obrigado, por si mesmo a mudar. Com alguma mudança que ocorra, a pressão interna tende a aumentar no sentido de outras mudanças, assim dá-se início a um ciclo positivo, que tem como ápice à compreensão ou progresso na realização de seus objetivos (do paciente).

A manutenção da cura de um paciente, tanto na utilização de um placebo como na psicoterapia, acontece, dentre outros fatores, pelo sentimento do poder pessoal adquirido (auto-estima), decorrente da crença do paciente de que foi ele mesmo quem realizou sua cura. Além disso, a percepção de sua nova condição de vida leva a um modo diferente de ver as coisas, o que geralmente torna menos provável a recorrência de comportamentos antigos. O fato das pessoas que se relacionam com o paciente terem, gradativamente, se adaptado aos seus novos comportamentos que foram surgindo durante todo o tratamento, forma um ambiente mais propício e seguro para a conservação da cura.

$\mathrm{Na}$ verdade, embora se conheça muito mais atualmente sobre os processos que ocorrem na intimidade do paciente durante uma psicoterapia, estamos ainda longe de chegar a um consenso sobre o que faz com que ocorram as mudanças que se observam tanto ao nível da simples redução de sintomas agudos, como alterações mais profundas e duradouras da personalidade (Cordioli, 1993). 
Felizmente, a medicina atual aceita o componente emocional no adoecer e na doença, isso é comprovado inclusive pela existência da psicossomática como uma especialização da medicina, aceita também o conceito de somatização, entendendo como concentração de energias psíquicas no corpo, causando algum sintoma físico ou doença, tal concepção é um diagnóstico comum entre os médicos. Entretanto, devido a interesses particulares, muitos não aceitam o que parece incontestável, o fato de se o componente interno (pensamento, sentimentos e emoções) está presente em um sentido, estará também presente em seu sentido inverso, ou seja, se tais componentes são capazes de modificar o organismo físico gerando doenças, também são capazes de modificá-lo gerando ou retornando á saúde.

Para Benoit (1989, citado em Castiel,1991), a fala como acontecimento biológico, age em contrapartida sobre suas próprias raízes biológicas. Assim podemos inferir que a fala influencia o corpo físico, podendo então ser a psicoterapia (terapia pela fala) considerada como algo que pode exercer uma função curativa (inconsciente) em algum sintoma físico organismo.

Um psicólogo, através da fala, tem acesso a componentes internos dos pacientes, podendo inclusive induzir uma modificação nos mesmos, assim é bem possível que alterando sentimentos e emoções envolvidas em determinados sintomas ou doenças, possa vir a diminuí-los ou elimina-los. O placebo também age de forma semelhante, incitando uma mudança interna, em nível psicológico, o que consequientemente gera uma mesma possibilidade de desfecho.

Segundo Williams (2004), em relação à questão de placebo e psicoterapia e, se é correto englobar na definição de placebo os procedimentos psicoterapeuticos, ele argumenta que o placebo é inerte fisicamente, mas não inerte psicologicamente. No entanto, se placebo é definido como algo que age sobre os mecanismos psicológicos do organismo, ao invés de mecanismos físicos, então se pode estender o conceito de placebo para o processo psicoterápico, que também, conceitualmente, age a nível da psiquê. Assim, todas as psicoterapias seriam consideradas placebos por definição. No entanto, segundo Williams, a divergência não é com a idéia de que uma técnica psicoterápica possa ser considerada um placebo, mas sim com a definição de placebo como agente que atua apenas a nível de mecanismos psicológicos.

A partir dos conceitos de placebo e psicoterapia, ao comparar ambos, possivelmente infere-se que as psicoterapias são inócuas, conclusão comprovadamente equivocada (Williams, 2004). Tal afirmação sugere que o entendimento geral de eficácia de um tratamento, baseia-se no fato de se considerar inerência como mais importante que o método utilizado. 
Uma psicoterapia é simplesmente um procedimento psicológico que não tem um poder inerente para produzir um efeito, mas se este procedimento funciona, devido aos procedimentos utilizados, então psicoterapia pode ser considerada placebo, sendo, entretanto, um tratamento ativo. Um tratamento ativo pode ser devido tanto ao seu poder inerente quanto ao efeito placebo.

O efeito placebo é então definido como os efeitos dos fatores comuns nos tratamentos bem sucedidos, podendo estar presente em tratamentos médicos, psicológicos e de outros profissionais. Um fator comum a estes tratamentos, é sem dúvida nenhuma, a empatia do profissional com o paciente (Williams, 2004).

\section{Conclusão}

As pesquisas mostram que o organismo é capaz de se mobilizar para diminuir ou até mesmo eliminar sintomas desagradáveis. Porém, o ser humano não confia nesta sua capacidade, pois ainda necessita de algo concreto que o incentive para essa mobilização, podendo ser, dentre vários exemplos, um remédio, um médico, uma atitude, um conselho, uma situação e até mesmo uma psicoterapia.

Pôde-se concluir que a psicoterapia atua semelhantemente ao placebo. Quando produz bons resultados, pode-se atribuir isto aos mesmos mecanismos do efeito placebo que são: indução da autoconfiança, uma sugestão eficaz, uma cura ou melhora atingida apenas por um fator externo inócuo que produziu efeitos internos curadores, dentre outros.

Observou-se que existe uma relação direta entre emoções, pensamentos e sentimentos (conteúdos internos) com o corpo físico-orgânico, e que ambos se modificam e são dependentes. Assim, da mesma forma que o indivíduo é capaz de somatizar problemas transformando-os em doenças, ele também é capaz de tratálas.

Em relação à eficácia do placebo, pôde-se inferir que a qualidade de vida em geral, e principalmente em termos de saúde, melhoraria consideravelmente se: houvesse uma aceitação mais ampla de sua existência; um maior conhecimento de suas causas; uma utilização consciente de seus princípios (sem que se necessitasse de algo concreto para isso). Ou seja, uma possível mudança conceitual, ideológica e de autoconfiança nas pessoas seriam suficientes para diminuir a necessidade da utilização de medicamentos, de consultas e de técnicas utilizadas atualmente na área de saúde, diminuindo inclusive, possíveis vícios e intoxicações por fármacos. Assim, tanto o investimento financeiro aplicado nessas áreas, bem como a utilização do tempo, poderia ser empregado na melhoria de outras necessidades pessoais 
ou coletivas. Uma generalização da autoconfiança individual, obtida pela eficácia da utilização dos placebos, formaria um contexto mais favorável para garantir eficácia em outras situações da vida particular.

\section{Referências}

AMARAL, J. R. A.; SABBATINI, R. M. Efeito Placebo: O Poder da Pílula de Açúcar. Disponível em <http://www.epub.org.br/cm/n09/mente/placebo1.htm>. Núcleo de Informática Biomédica Publicado em 25 de julho de 1999. Acesso em 10 março 2004.

BALLEIRO, E. M.; BALLEIRO, C. O. Efeito Placebo e o Efeito Nocebo nos Procedimentos Terapêuticos. Disponível em <http://www.cibersaude.com.br/index1.asp>. Publicado em abril de 2000. Acesso em 11 março 2004.

BALLONE, G. J.; ORTOLANI, I. V. O Placebo e a arte de curar, 2003 in. PsiqWeb, internet, disponível em <http://www.virtualpsy.org/trats/placebo.html $>$. Acesso em 15 março 2004.

BECHELLI, L. P. C.; SANTOS, M. A. Psicoterapia de grupo e considerações sobre o paciente como agente da sua própria mudança. Rev latino - am Enfermage, maio/ junho 2002, vol.10, $\mathrm{n}^{\circ} 3$.

BENETTON, L. G. Temas de Psicologia em saúde: A relação Profissional paciente. $1^{\text {a }} \mathrm{ed}$. São Paulo: ATIS, 2002.

CAMPOS, E. Aspectos Psicossomáticos das Doenças Cardiovasculares e o Efeito Placebo. Jornal Bras. Psiquiatr, novembro/ dezembro de 1985, vol $34 \mathrm{n}^{\circ}$ 6, p 405-410.

CASTIEL, L. D. Psicossomática e eficácia: Além do Principio do Placebo. Jornal Bras. Psiquiatr, junho de 1991, vol. $40 \mathrm{n}^{\circ}$ 5, p 267-272.

CELESTINO, C, A. O uso do placebo no tratamento de mulheres Climatéricas. Rev. Ginecol Obstet, São Paulo, 1992, vol. 3, n 1, p 105-110.

CORDIOLI, A. V. Psicoterapias: Abordagens Atuais: Porto Alegre: Artes Médicas, 1993.

CORTESE, S. S. A ética na pesquisa clínica. Rev. Psiquiatr, janeiro/abril 1999, vol. 21, n ${ }^{\circ}$, p 23-29.

ELKIS, H.; GATTAZ, W. F. Algumas recomendações para estudos com placebo. Rev. Bras. Psiquiatr, dezembro 2000, vol. 22, $\mathrm{n}^{\circ} 4$.

EPSTEIN, I. Placebo, Placeo, (Lat: Agradar, fazer bem), Nocebo Noceo (Lat: Fazer mal. prejudicar) e os efeitos adversos dos medicamentos anunciados nas bulas. Disponível em <http://www.projetoradix.org/Artigos/comsaudeVI/artigos/gt6b placebo.pdf>. UMESP, cátedra UNESCO. Publicado em 22 de abril de 2002. Acesso em: 07 março 2004.

FISH, J. M. Placebo Terapia: A Fé No Processo Da Cura. Campinas: PAPURIS, 1988. Traduzido por GOMES, J. C. V. Original, 1973.

FOUCAULT, M. História da Loucura na idade clássica: São Paulo: Perspectiva 3 ed, 1991. 
Traduzido por NETTO, J. T. C.Original, 1972.

GERHARDT, I. Efeito Placebo: mistério desvendado. Disponível em <http:// www.geocities.com/paraciencia/placebo.html $>$. Publicado em 10 de agosto de 2001. Acesso em: 10 março 2004.

HOLDEN, C. Drugs and Placebos Look Alike in the Brain. Science, 8 de fevereiro 2002, vol. $295 n^{\circ} 947$.

HORGAN, J. A Mente Desconhecida: Por Que a ciência não consegue replicar, medicare explicar o cérebro humano. São Paulo: Companhia das letras, 2002. Traduzido por MOTTA, L. T. Original, 1955.

IACOPONI, E.; MARCOLINO, J. A . M. Escala de aliança Psicoterápica da Califórnia na versão do paciente. Rev Bras. Psiquiatr, junho de 2001 vol. 23, n 2.

ROSSI, E. L. A Psicobiologia da Cura Mente-Corpo: Novos Conceitos de Hipnose Terapêtica. Campinas: Editorial Psy Ltda, 2 ${ }^{\mathrm{a}}$ ed revisada 1997. Traduzido por MORAES, A. R. P. Original, 1993.

SCAZUFCA, M.; MATSUDA, C. M. C. B. Revisão sobre a eficácia de psicoterapia vs. farmacoterapia no tratamento de depressão em idosos. Rev. Bras. Psiquiatr, abril 2002, vol. 24 supl.1.

STEPHEN, M.D. Remissão Espontânea e Efeito Placebo. Disponível em <http:// www.geocities.com/quackwatch/placebo.html > . Publicado em 22 de abril de 2002. Acesso em 15 março 2004.

STERNBERG, E. M.; GOLD, F. A interação corpo-mente nas doenças. Rev. Scientrific American Brasil, 2004, ed especial n ${ }^{\circ}$ 4, p 84-91.

TOSTES, L. R. M. O Efeito Placebo e os Aspectos Inespecífiocs das Psicoterapias. Jornal Bras. Psiquiatr, novembro/dezembro de 1985, vol 34 n 6, p 395-398.

Uso do placebo: aspectos bioéticos. Rev. Assoc. Med. Bras, julho/setembro 2002, vol. 48, $\mathrm{n}^{\circ}$ 3.

WILLIAMS, S. S.; PODD, J. The Placebo effect: Dissolving the Expectancy Versus Condidioning Debate. Psychological Bulletin, 2004, vol. 130, n 2, p 324-340 